\title{
Experimental Investigation on Chloride Penetration Properties of Cement-based Materials Containing Graphene Nanoplatelets
}

\author{
Qiong LIU ${ }^{1, a,{ }^{*},}$ Run-Dong GAO ${ }^{1, b}$ \\ ${ }^{1}$ Shanghai Key Laboratory of Engineering Structure Safety, Shanghai Research Institute of Building \\ Sciences, Shanghai 200032, China \\ aliuqiongleo@163.com, bgrdong_1@163.com \\ ${ }^{*}$ Corresponding author
}

Keywords: Graphene Nanoplatelets, Cement-based Materials, Chloride Penetration.

\begin{abstract}
Graphene nanoplatelets (GNPs), as new candidates for nano-sized additives, are potential to improve the mechanical and durability performance of concrete. On the other hand, GNPs will act as conductive fillers to lower the conductivity of concrete, which may induce corrosion problem due to high ions transportation rate. To grasp which effect plays a key role in ions transportation, rapid chloride penetration experiments were conducted to find the influence of GNPs concentration, including $0 \%, 0.05 \%, 0.1 \%$ and $0.2 \%$ by the amount of cement, on the chloride penetration depth. Mercury intrusion porosimetry (MIP) was used to detect the porosity characteristics for understanding the enhancing mechanism. Results show that the chloride penetration depths of mortar specimens decrease as the increasing of GNPs concentrations. The addition of GNPs in mortar can minimize the pores' size and quantity according to MIP analysis, which contributes to better durability on chloride penetration.
\end{abstract}

\section{Introduction}

Cement-based materials, including mortar and concrete, have been widely used for various types of structures, while, the disadvantages of brittle mechanical properties and limited workability set barriers for utilizing them. In addition, the progress in building industry calls for high performance cementitious materials. The idea using additives to enhance cement paste has attracted keen interests of related researchers ${ }^{[1]}$.

In these recent years, nano-sized additives have been used in cementitious materials widely to improve their mechanical properties ${ }^{[2]}$. Nano-particles can fill the voids in cement paste, resulting in lower porosity and high strength ${ }^{[3]}$. Ji's investigation indicated that nano addictives can reduce the water permeability of concrete ${ }^{[4]}$. Nano-particles can also improve the resistance to calcium leaching ${ }^{[5]}$. Kong et al. reported that despite the existence of the weak zone between cement paste and agglomerates, and the high porosity of agglomerates, nano fillers can still be effective in blocking the ingress of chloride ions ${ }^{[6]}$.

Different from pristine graphite, Graphene nanoplatelets (GNPs) are single-layer or few-layer structures, which were newly discovered in $2004^{[7]}$. Promising research works have been done on the mechanical properties of cementitious composites strengthened by GNPs. The addition of GNPs, possessing great conductive properties, can improve the ions migration ability in cementitious composites which may lead to penetration or durability problems ${ }^{[8]}$. On the other hand, nano-sized additives can reduce the micro porosity resulting in good durability ${ }^{[2]}$. Which effect would play the key role in concrete containing GNPs? To settle this contradiction, a rapid chloride penetration test is performed in this study to see the influence of GNPs concentration on the penetration depth in cement-based mortar. Mercury intrusion porosimetry (MIP) is carried out for understanding the fundamental mechanisms of GNPs enhancing cementitious matrix. 


\section{Experimental Test}

\section{Materials Preparation}

In this investigation, standard type 52.5 cement in terms of Chinese standard "Common Portland cement" (GB175-2005), was used for preparing the mortar specimens. Sieved dry sand, smaller than $2.36 \mathrm{~mm}$, was prepared to make the mortar. One type of GNPs from The Sixth Element Inc. (Changzhou, China) was used as additives in mortar. According to the factory inspection report, GNPs have the properties listed in Table 1. Polycarboxylate superplasticizer was used as surfactant to assist dispersing GNPs into aqueous suspension.

Tab.1 The Properties of GNPs Used in the Tests

\begin{tabular}{ccccc}
\hline $\begin{array}{l}\text { Factory } \\
\text { number }\end{array}$ & Thickness $(\mathrm{nm})$ & $\begin{array}{c}\text { In-plane } \\
\text { diameter }(\mu \mathrm{m})\end{array}$ & $\begin{array}{c}\text { Specific surface } \\
\operatorname{area}\left(\mathrm{m}^{2} / \mathrm{g}\right)\end{array}$ & Appearance \\
\hline SE1231 & $\sim 5$ & $\sim 6.8$ & 191.8 & Dark powder \\
\hline
\end{tabular}

\section{Specimens Casting and Curing}

Four types of GNPs concentration $(0 \%, 0.05 \%, 0.1 \%$ and $0.2 \%)$, whose mix proportions are listed in Table 2, are used in this study to grasp the influence of GNPs on chloride penetration properties. Among them, the GNPs concentration 0\% meant contrast mix labeled as NM. GM0.05 represents that its GNPs concentration was $0.05 \%$. The other mix proportions' names followed the same rule. Extra superplasticizer was added into GM0.2 because its workability was much worse than other batches. After adding extra superplasticizer, GM0.2 showed great flowability by comparing the slumps with the others.

Tab.2 The Mix Proportion

\begin{tabular}{ccccccc}
\hline Name & $\begin{array}{c}\text { Cement } \\
(\mathrm{g})\end{array}$ & $\begin{array}{c}\text { Sand } \\
(\mathrm{g})\end{array}$ & $\begin{array}{c}\text { Wate } \\
\mathrm{r}\end{array}$ & $\begin{array}{c}\text { Graphene } \\
(\mathrm{g})\end{array}$ & $\begin{array}{c}\text { Superplasticizer } \\
(\mathrm{g})\end{array}$ & $\begin{array}{c}\text { Slump } \\
(\mathrm{mm})\end{array}$ \\
\hline $\mathrm{NM}$ & 205.4 & 616.3 & 123.3 & 0.000 & 2.0 & 13 \\
GM0.05 & 205.4 & 616.3 & 123.3 & 0.103 & 2.0 & 12 \\
GM0.1 & 205.4 & 616.3 & 123.3 & 0.205 & 2.0 & 12 \\
GM0.2 & 205.4 & 616.3 & 123.3 & 0.411 & 3.0 & 39 \\
\hline
\end{tabular}

GNPs are in micro or nano scale, which turns their dispersion in water aqueous suspension into a challenge. For their size, use of physical methods, such as high shear mixing and ultra-sonication, or chemical methods, such as non-covalent surface modification by surfactants, alone is hard to separate them from each other ${ }^{[9]}$. In this study, ultra-sonication and surface modification were jointly used to disperse GNPs fillers into water.

Prior to casting of mortar, GNPs were first ultra-sonicated with the aid of water and Polycarboxylate superplasticizer for half an hour. The dry components for mixing mortar, including cement and sand, were stirred in a mixer. As stirring, the GNPs water suspension was added into the container of the mixer. After 3 more minutes being stirred, the mortar was casted into moulds with dimensions of $50 \times 50 \times 50 \mathrm{~mm}$ under the assistance of vibrator. For the chloride penetration test, a steel bar with diameter of $6 \mathrm{~mm}$ was inserted into each fresh mortar specimen. During casting and curing, the recommendation of ASTM C31 standard was followed. The specimens were demolded 24 hours after casting, and then immediately placed in an environmental chamber for standard curing for 28 days.

Owing to a limited amount of mortar paste that could be produced, the workability of the fresh mortars was assessed by a mini-slump test ${ }^{[10]}$. The dimensions of the mini-slump cone were: top diameter $30 \mathrm{~mm}$, bottom diameter $50 \mathrm{~mm}$, and height $65 \mathrm{~mm}$. The slump test values are shown in Table 2 . 


\section{Physical and Mechanical Tests}

An electron universal test machine (SANS T60) was used to test the compressive strength of the cube specimens. For each type of mortar, three cubes were tested to estimate the average. The loading rate in the test was about $2000 \mathrm{~N} / \mathrm{s}$ as recommended by the ASTM 109. In addition, the procedure for water absorption measurement complied with the standard recommendations.

\section{Rapid Chloride Penetrability Test}

Steel bars, diameter $6 \mathrm{~mm}$, were embedded into mortar specimens and the outside parts were coated with epoxy to prevent corruption. A stainless steel bar was connected with the positive electrode of a constant current instrument, and the negative electrode was connected with all the specimens. The specimens and the stainless steel bar were immersed into $6 \% \mathrm{NaCl}$ solution with the depth of $40 \mathrm{~mm}$ as shown in Fig.1. A continuous electrical current $(2 \mathrm{~mA})$ was implemented between the stainless steel bar and the specimens. After 7 days corrosion, the specimens were split. The chloride penetration depth of each specimen was distinguished by spraying silver nitrate solution (concentration: $0.1 \mathrm{~mol} / \mathrm{L}$ ) on the cross sections of broken specimens due to the generation of white sediment AgCl.

(a)

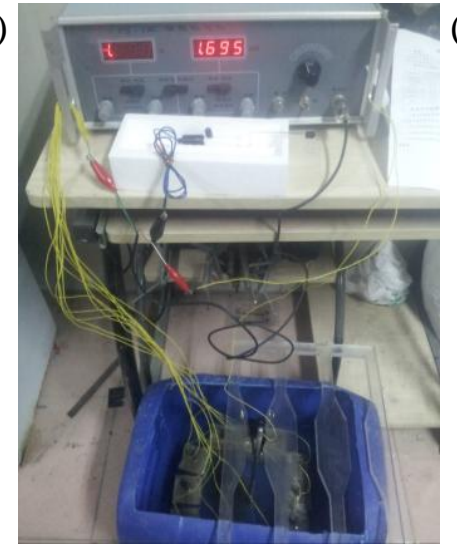

(b)

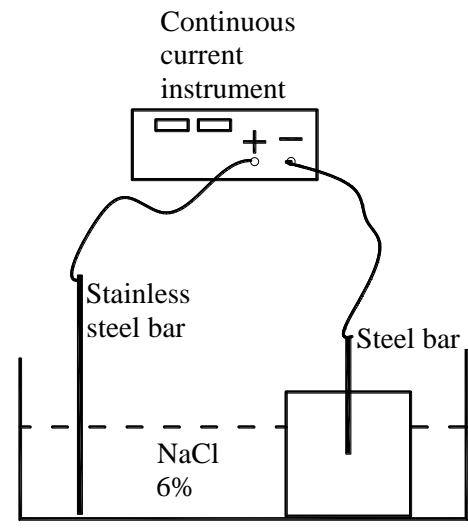

Fig.1 Rapid Chloride Penetration Test Setup: (a) Photo (b) Sketch Drawing

\section{Mercury Intrusion Porosimetry (MIP)}

The pore size distribution in cementitious matrix was determined with the method of MIP. In this test, Autopore IV 9500 was used to conduct the test by applying different levels of pressure to a mortar sample immersed in mercury. The instrument, known as a porosimeter, employs a pressurized chamber to force mercury to intrude into the voids in cementitious mortar. As pressure increases, the filling proceeds to smaller and smaller pores. The pressure to intrude mercury into the sample's pores is proportional to the size of pores. With this method, the porosity characteristic, such as pore size, distribution, volume and density, of cement-based materials can be measured.

\section{Results and Discussion}

\section{Physical and Mechanical Properties}

The measured water absorption and compressive strength of four batches of mortar are illustrated in Table 3. Normal mortar shows $9.23 \%$ water absorption and $35.7 \mathrm{MPa}$ compressive strength. All the batches containing GNPs have lower water absorption than the contrast batch. Additionally, GM0.1 has the lowest absorption $8.89 \%$.

GM0.05 and GM0.1 are enhanced with GNPs by the percentages $18 \%$ and $22 \%$ respectively according to the compressive strengths shown in Table3. GM0.2 shows a slight lower strength than normal mortar. This may result from that more water reducer, which can generate more air bubbles in 
$\operatorname{mortar}^{[11]}$, was used in GM0.2. Through comparing the absorption and strength of each batch, it can be found that lower absorption basically means higher strength.

Tab.3 The Physical and Mechanical Properties

\begin{tabular}{ccc}
\hline Name & Absorption (\%) & Compressive strength (MPa) \\
\hline NM & $9.23 \%$ & 35.7 \\
GM0.05 & $9.10 \%$ & 42.3 \\
GM0.1 & $8.89 \%$ & 43.7 \\
GM0.2 & $9.17 \%$ & 35.3 \\
\hline
\end{tabular}

\section{Chloride Penetration Properties}

After 7days rapid chloride penetration, the penetrated front can be seen by spraying $\mathrm{AgNO}_{3}$ on the cut section surfaces of the specimens because white sediment $\mathrm{AgCl}$ is generated as shown in Fig.2, from which, the penetration depth can be measured. For each sample, six penetration depths are measured and the mean value is calculated. By plotting their penetration depth in a bar chart as shown in Fig.3, it can be clearly seen that the depth drops as the increasing of GNPs concentration.
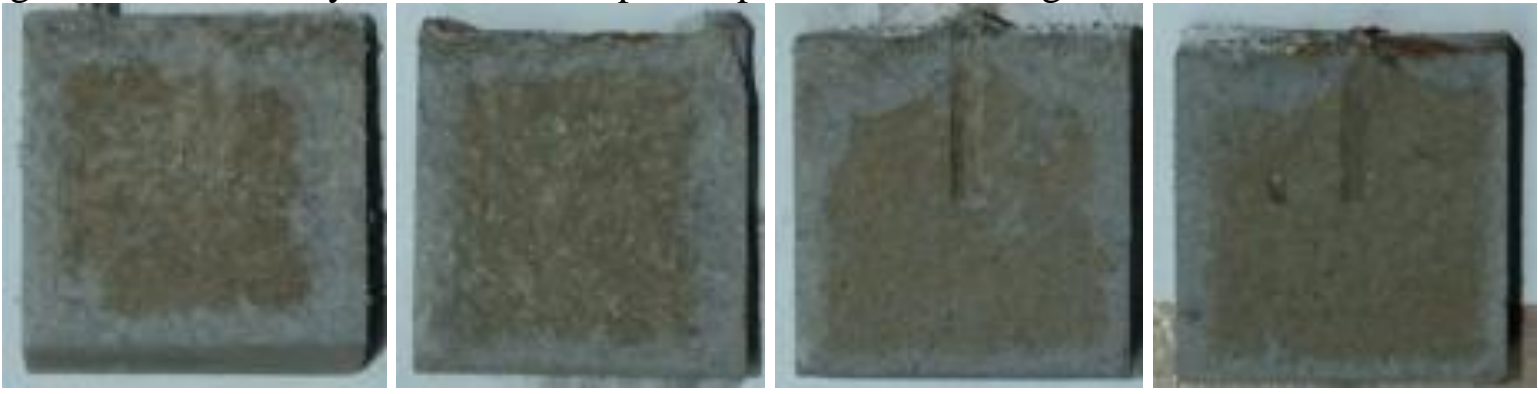

Fig.2 The Penetration Areas (from Left to Right: NM, GM0.05, GM0.1 and GM0.2)

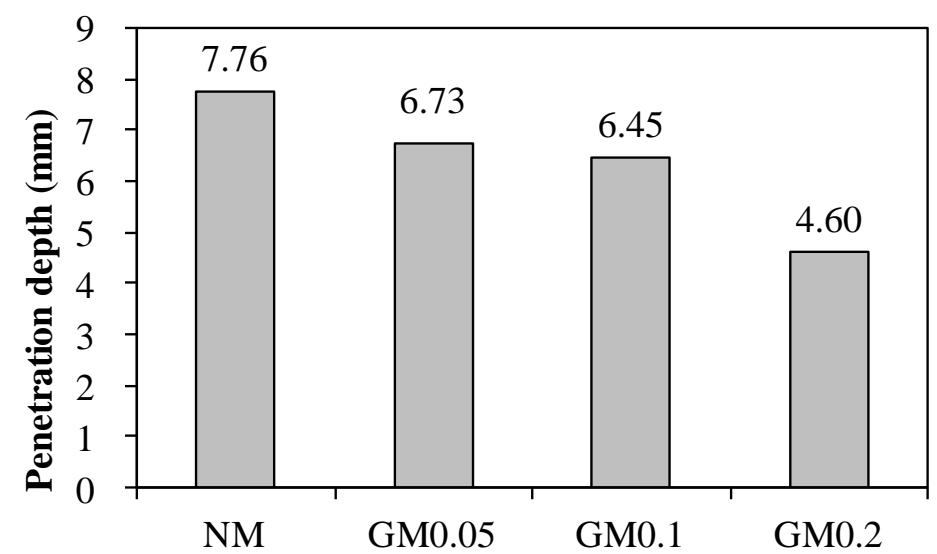

Fig.3 The Penetration Depth

\section{Mercury Intrusion Porosimetry Analysis}

With mercury intrusion analysis, some basic results are summarized in Table 4 . The total intrusion volume decreases from NM, GM0.05, GM0.1 to GM0.2, which means there are less and less pores as the increasing amount of GNPs infilled in mortar. The porosity values in Table 4 also show this trend, although there is a slight exception on GM0.05. The total pore area can also indicate this tendency remarkably. Additionally, NM has lowest bulk density and apparent density than those specimens 
containing GNPs. Conclusively the intrusion analysis results show that the addition of GNPs can densify cement-based composites.

To see the pore distribution in mortar specimens, the cumulative intrusion curves are plotted in Fig 4. Through comparing the curves, it can be found that GM0.05 has less big pores (diameter from $100 \mathrm{~nm}$ to $10000 \mathrm{~nm}$ ) than contrast mortar NM. While, as to the pores smaller than $100 \mathrm{~nm}$, GM0.025 and NM has similar quantity and distribution. GM0.1 has similar big pores distribution as NM, while, less small pores (diameter smaller than 100nm) can be observed in GM0.1. The curve of GM0.2 is located totally under that of contrast mix, which indicates GM0.2 has less both small pores and big pores. In summary, the addition of GNPs densifies mortar by decreasing its pore size or pore quantity, or even both. As a result, it can be concluded that the chloride penetrating resistance of mortars are improved with the addition of GNPs through densifying mortars' micro structure.

Tab.4 Intrusion Results Summary

\begin{tabular}{cccccc}
\hline & $\begin{array}{c}\text { Total intrusion volume } \\
(\mathrm{mL} / \mathrm{g})\end{array}$ & $\begin{array}{c}\text { Total pore area } \\
\left(\mathrm{m}^{2} / \mathrm{g}\right)\end{array}$ & $\begin{array}{c}\text { Bulk density } \\
(\mathrm{g} / \mathrm{mL})\end{array}$ & $\begin{array}{c}\text { Apparent density } \\
(\mathrm{g} / \mathrm{mL})\end{array}$ & $\begin{array}{c}\text { Porosity } \\
(\%)\end{array}$ \\
\hline $\mathrm{NM}$ & 0.090 & 15.440 & 2.043 & 2.503 & 18.353 \\
$\mathrm{GM} 0.05$ & 0.088 & 14.281 & 2.104 & 2.582 & 18.512 \\
$\mathrm{GM} 0.1$ & 0.074 & 8.564 & 2.159 & 2.572 & 16.057 \\
$\mathrm{GM} 0.2$ & 0.071 & 8.945 & 2.146 & 2.534 & 15.307 \\
\hline
\end{tabular}

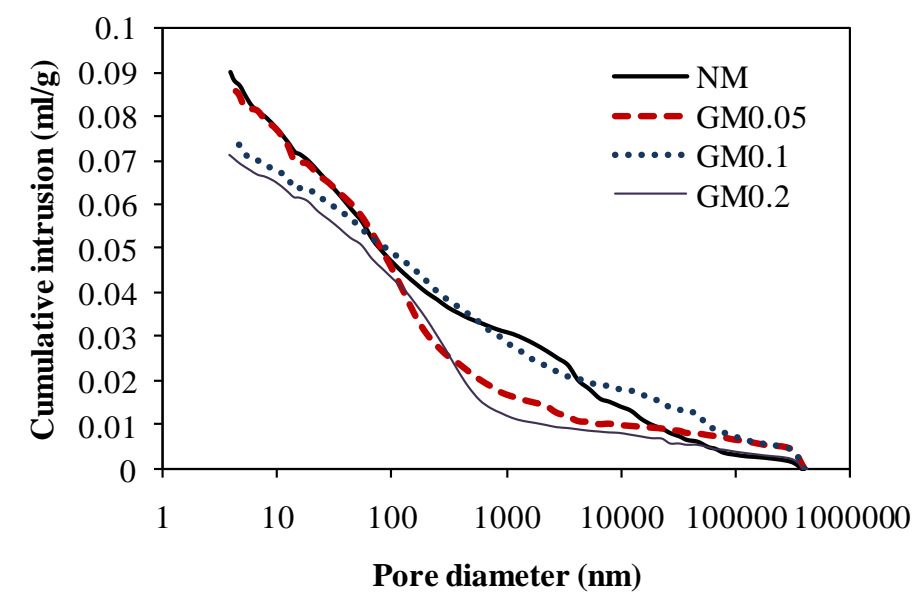

Fig.4 Cumulative Pore Size Distribution Obtained for Different Mortars

\section{Summary}

In this investigation, the effects of GNPs on chloride penetration resistance in cement-based mortar are studied experimentally. The results show that the addition of GNPs can enhance the compressive strength of cementitious materials and decrease their water absorption. As the increasing of GNPs' concentration, the chloride penetration depth drops dramatically. According to MIP test, it can be found that less pores and smaller pores can be detected in cement-based mortar containing more GNPs. This contributes the mechanism that mortars filled with GNPs have better chloride penetration resistance.

\section{Acknowledgement}

This research was financially supported by the Shanghai Rising-star Program (14QB1403800). 


\section{References}

[1] V. Kumar, Protection of steel reinforcement for concrete - a review, Corros. Rev. 16 (4) (1998) 317-358.

[2] K. Sobolev, M. Ferrada-Gutierrez, How nanotechnology can change the concrete world: part I, Am. Ceram. Soc. Bull. 84 (2005) 14-17.

[3] Z.S. Metaxa, J.W.T. Seo, M.S. Konsta-Gdoutos, et al, Highly concentrated carbon nanotube admixture for nano-fiber reinforced cementitious materials, Cem. Concr. Compos. 34 (2012) $612-615$.

[4] T. Ji, Preliminary study on the water permeability and microstructure of concrete incorporating nano-SiO 2 , Cem. Concr. Res. 35 (2005) 1943-1947.

[5] J.J. Gaitero, I. Campillo, A. Guerrero, Reduction of the calcium leaching rate of cement paste by addition of silica nanoparticles, Cem. Concr. Res. 38 (2008) 1112-1118.

[6] D. Kong, X. Du, S.Wei, H. Zhang, et al, Influence of nano-silica agglomeration on microstructure and properties of the hardened cement-based materials, Constr. Build. Mater. 37 (2012) 707-715.

[7] K.S.A. Novoselov, A.K. Geim, S.V. Morozov, et al. Two-dimensional gas of massless Dirac fermions in graphene, Nature, 438 (7065) (2005) 197-200.

[8] J. P. Hwang, M. S. Jung, M. Kim, et al. Corrosion risk of steel fiber in concrete. Constr. Build. Mater. 101(2015): 239-245.

[9] B. Han, X. Guan, J. Ou. Application of ultrasound for preparation of carbon fiber cement-based composites. Mater. Sci. Technol. 17(3) (2009) 368-372.

[10] D.L. Kantro, Influence of water-reducing admixtures on properties of cement paste- a miniature slump test. Cement Concrete Aggregate, 2(1980): 95-102.

[11] L. Du, K. J. Folliard, Mechanisms of air entrainment in concrete. Cem. Concr. Res. 35 (8) (2005) 1463-1471. 